\title{
Fractured guidewire fragment on the peripheral side of a malignant biliary obstruction: successful removal using a biliary balloon dilation catheter
}

Fractured guidewire fragments in the bile duct need to be removed because they may lead to infected liver hematoma or cholangitis [1-4]. We report the successful endoscopic removal of a fractured guidewire fragment on the peripheral side of a malignant biliary obstruction using a biliary balloon dilation catheter.

A 73-year-old woman underwent detailed tests for obstructive jaundice. Contrast-enhanced computed tomography showed a mass lesion in the hilar bile duct ( $\triangleright$ Fig. 1 a). Endoscopic retrograde cholangiopancreatography was then performed. Cholangiography showed a stricture in the hilar bile duct ( $\mathbf{F i g} \mathbf{1} \mathbf{b}$ ). We then performed peroral cholangioscopy (POCS) (SpyGlass DS; Boston Scientific, Marlborough, Massachusetts, USA) for accurate diagnosis ( Video $\mathbf{1}$ ). An irregular papillary protrusion, which was the suspected malignancy, was confirmed by POCS ( $>$ Fig. 2). A guidewire (0.025-inch diameter, 450-cm length, angled tip; VisiGlide 2; Olympus, Tokyo, Japan) was negotiated to the posterior right intrahepatic bile duct using POCS. As the guidewire was being withdrawn, it fractured. The fractured fragment was located on the peripheral side of the malignant biliary obstruction ( $>$ Fig.3). The narrowness of the POCS channel $(1.2 \mathrm{~mm})$ may have caused friction and ultimate fracturing of the guidewire. Another guidewire was placed over the guidewire fragment, and a biliary balloon dilation catheter (MaxForce; Boston Scientific) (> Fig.4) was then inserted. It was inflated to the diameter of the bile duct, allowing it to adhere to the guidewire fragment, and carefully pulled until the fragment was on the papilla side of the malignant biliary obstruction. Finally, the fragment was removed using forceps under direct view of POCS ( Fig. 5).
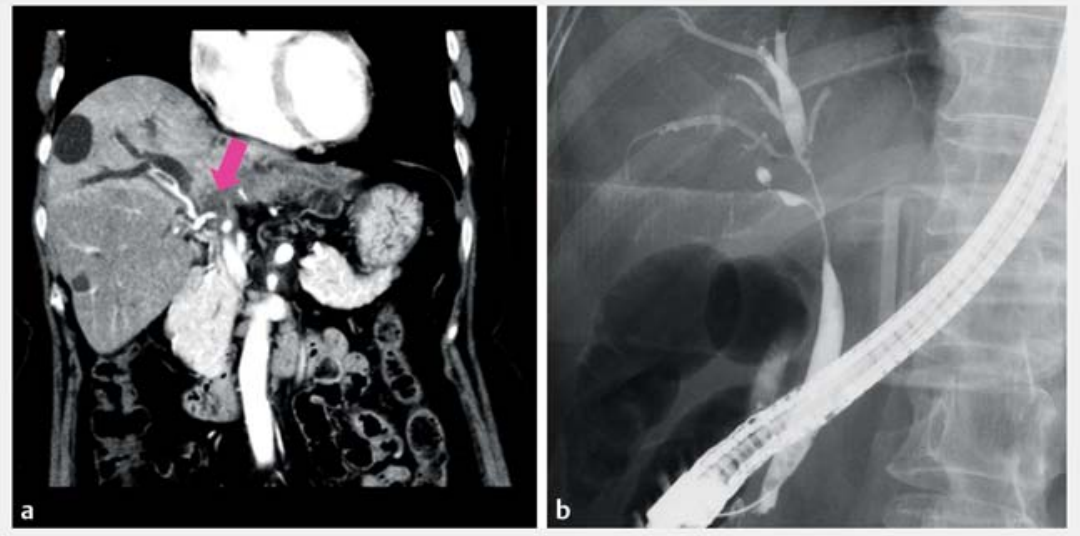

- Fig. 1 Computed tomography and endoscopic retrograde cholangiopancreatography findings. a Contrast-enhanced computed tomography showing a mass lesion in the hilar bile duct (arrow). b Cholangiography showing a stricture in the hilar bile duct.

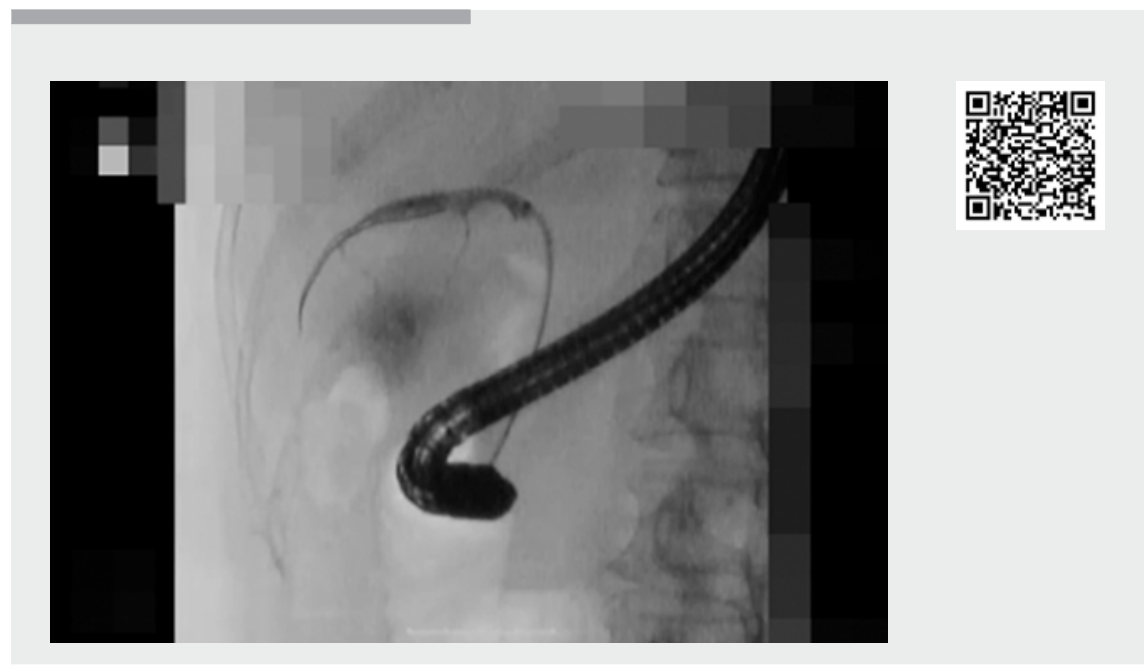

$\checkmark$ Video 1 Successful endoscopic removal of a fractured guidewire fragment on the peripheral side of a malignant biliary obstruction using a biliary balloon dilation catheter.

Although endoscopic removal of a fractured guidewire fragment has been reported $[3,5]$, removal from the peripheral side of the malignant biliary obstruction is thought to be difficult and has not previously been demonstrated. The shape of this balloon catheter was useful in allowing it to adhere to the guidewire fragment.

Endoscopy_UCTN_Code_CPL_1AK_2AD 


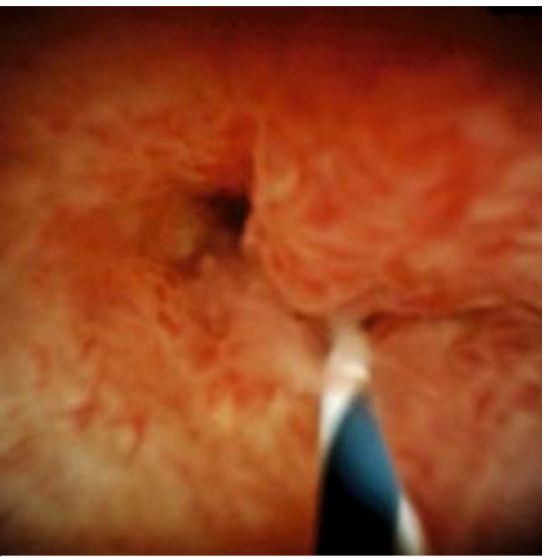

- Fig. 2 Peroral cholangioscopy findings. An irregular papillary protrusion, which was the suspected malignancy, was confirmed by peroral cholangioscopy.

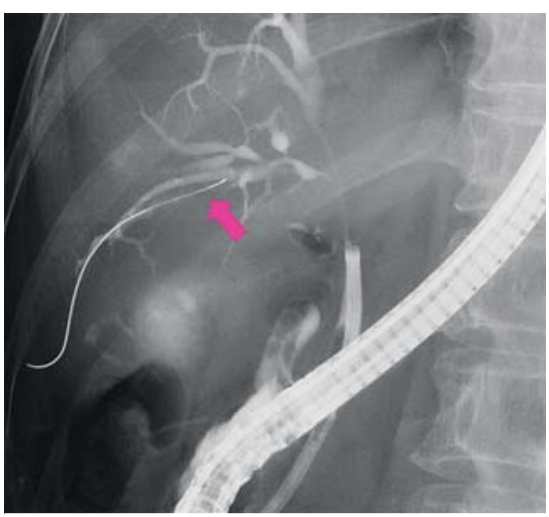

- Fig. 3 The guidewire fragment was located on the peripheral side of the malignant biliary obstruction.

\section{Competing interests}

The authors declare that they have no conflict of interest.

The authors

Yuki Tanisaka, Shomei Ryozawa, Masafumi Mizuide, Akashi Fujita, Tomoya Ogawa, Tatsuya Noguch, Tomoaki Tashima Department of Gastroenterology, Saitama Medical University International Medical Center, Saitama, Japan

\section{Corresponding author}

\section{Yuki Tanisaka, MD, PhD}

Department of Gastroenterology,

Saitama Medical University International

Medical Center, 1397-1, Yamane, Hidaka,
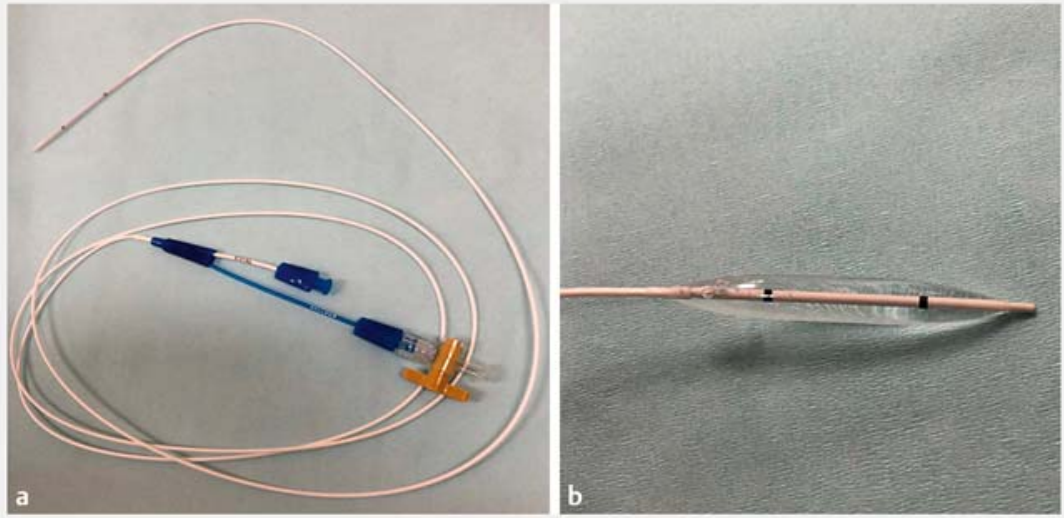

- Fig. 4 Biliary balloon dilation catheter (MaxForce; Boston Scientific, Marlborough, Massachusetts, USA).

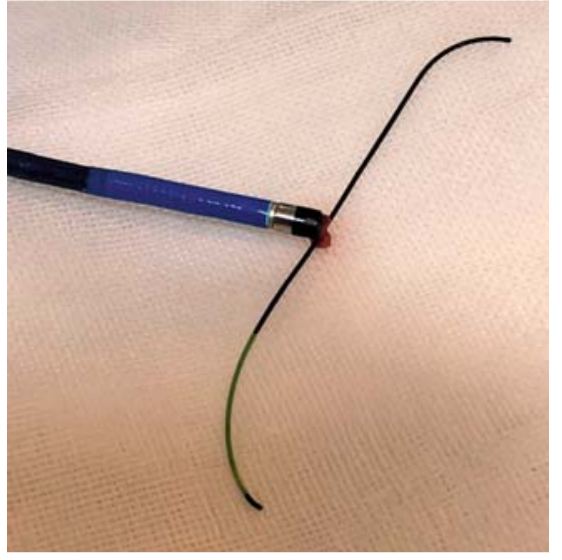

- Fig. 5 The removed guidewire fragment.

Saitama 350-1298, Japan

Fax: +81-42-9844589

tanisaka1205@gmail.com

\section{References}

[1] Heinerman M, Mann R, Boeckl O. An unusual complication in attempted non-surgical treatment of pancreatic bile duct stones. Endoscopy 1993; 25: 248-250

[2] Ortega Deballon P, Fernández Lobato R, García Septiem J et al. Liver hematoma following endoscopic retrograde cholangiopancreatography (ERCP). Surg Endosc 2000; 14: 767

[3] Fry LC, Linder JD, Monkemuller KE. Cholangitis as a result of hydrophilic guidewire fracture. Gastrointest Endosc 2002; 56: 943-944

[4] Nishikawa Y, Uza N, Yamauchi Y et al. Successful endoscopic removal of fractured guidewire fragments from a peripheral bile duct using a biliary stent delivery system and biopsy forceps. Endoscopy 2018; 50: E279-E280

[5] Burdick JS, Schmalz M], Geenen JE. Guidewire fracture during endoscopic sphincterotomy. Endoscopy 1993; 25: 251-252

\section{Bibliography}

Endoscopy 2021; 53: E183-E184

DOI 10.1055/a-1230-3170

ISSN 0013-726X

published online 2.9.2020

(c) 2020. Thieme. All rights reserved.

Georg Thieme Verlag KG, Rüdigerstraße 14, 70469 Stuttgart, Germany

\section{ENDOSCOPY E-VIDEOS}

https://eref.thieme.de/e-videos

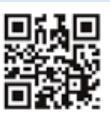

Endoscopy E-Videos is a free access online section, reporting on interesting cases and new techniques in gastroenterological endoscopy. All papers include a high quality video and all contributions are freely accessible online.

This section has its own submission website at https://mc.manuscriptcentral.com/e-videos 